\title{
Смена модели продаж: от продукта к функциям. Фотонные и оптические технологии на выставке ИНнОПРОМ-2019
}

Н. Л. Истомина, Л. В. Карякина, АО «РИЦ «ТЕХНОСФЕРА», www.photonics.su, Москва, Россия

\begin{abstract}
Лазерные и оптические технологии открывают новые возможности для создания качественных продуктов. Но не только знание процессов производства продукта определяет превосходство компании. Умение обеспечивать удаленную диагностику и мониторинг привело к более эффективной монетизации технологии. Бизнесмодель продаж технологических функций заменяет бизнес-модель продаж продукта, опережающего своих конкурентов. В обзоре представлены технологические компании и их интегрированные решения с использованием фотонных технологий, применяемые в условиях кластерной и сетевой моделей развития экономики.
\end{abstract}

Ключевые слова: технические выставки, лазерное упрочнение, лазерная наплавка, лазерная резка, лазерная маркировка, кодирование продукции, оптические технологии, бизнес-модель продаж функций, концепция цифрового производства, автоматизации доставки инструментов к рабочему пространству

\section{Shift Model of Sales: From Product to Functions. Photon and Optical Technologies at the Industrial Fair INNOPROM-2019}

\section{N. L. Istomina, L. V. Karyakina, APC TECHNOSPHERA JSC, www.photonics.su, Moscow, Russia}

Laser and optical technologies open up new possibilities for creating quality products. But not only knowledge of product manufacturing processes determines the superiority of the company. The ability to provide remote diagnostics and monitoring has led to a more effective monetization of technology. The business model of sales of technological functions replaces the business model of sales of a product that is ahead of its competitors. The review presents technology companies and their integrated solutions based photon technologies that are used in cluster and network models of economic development.

Keywords: industrial fair, laser hardening, laser cladding, laser cutting, laser marking, product coding, optical technologies, function sales business model, digital production concept, automation of tool delivery to the workspace 
В 2019 году экспозицию выставки ИННОПРОМ объединила тема "Цифровое производство: интегрированные решения". Под этим лозунгом свою продукцию и услуги представили такие разные компании, что описать их изделия в одном обзоре оказалось затруднительно. Тем более - выделить те из них, которые связаны с фотоникой. По-честному, все они использовали в автоматизации своего производства либо техническое зрение, либо лазерную обработку материалов, либо передачу сигналов с помощью оптического волокна, либо новые дисплейные технологии. Распространенной рекламной бизнес-моделью на выставке стала партнерская модель: большинство компаний объединяли свои экспозиции на общем стенде вокруг "градообразующих" лидеров - РЖД, FANUC, Omron, «Швабе», "Росатом" и т.д.

Посетители выставки владеют хорошим уровнем технических знаний и знакомы со специализированной

Компания KUKA вместе с партнерами под общим брендом "Проф ІТ-групп" представила комплексные проекты, объединенные оборудованием фирмы KUKA, роботов KUKA и различных IT-систем. Руководитель направления продаж компании «Проф IT-групп" Андрей Шаверин рассказывает:

Мы представили несколько систем, которые включают в себя MES-системы на базе системы 1C-MES нашей собственной разработки. MES - это система оперативного планирования производства. Программный продукт “Оперативное управление производством" предназначен для решения оперативных производственных задач, повышения эффективности управления и контроля процесса производства. С ее помощью можно сформировать заказ на производство и в автоматическом режиме подать на робота, а робот отрабатывает этот заказ. Алгоритм позволяет размещать технологические операции на оси времени рабочих центров без дискретных интервалов, с учетом ограничений, вытекающих из условия предшествования технологических операций и доступности основных рабочих центров.

Владимир Деккер, сотрудник компании KUKA, показал промышленную передвижную платформу с лазерными сканерами:

На выставке представлена новая разработка полностью автономная мобильная платформа для организации внутризаводской логистики. Мобильная платформа оснащена четырьмя колесами Илона, благодаря которым обеспечивается высокая маневренность: платформа может разворачиваться на одном месте, передвигаться в продольном и поперечном направлении, а также в диагональ- информацией в своих областях деятельности, но не все из них владеют знаниями новых фотонных и лазерных технологий. Ряд компаний развивают свой многолетний бизнес в тепличных условиях государственной поддержки в соответствии с первоначально принятой бизнес-моделью, с изначально действующим иерархическим порядком организации производства, что снижает их конкурентоспособность. Экспозиция выставки ИННОПРОМ-2019 стала представлением новых технологий, новых концепций развития бизнеса в условиях кластерной и сетевой моделей развития экономики.

Начнем свой путь по экспозиции выставки с автоматизации доставки инструментов к рабочему пространству. Конечно, тут балом правят роботы. Ловкие желтые, светло-зеленые и оранжевые манипуляторы FANUC и KUKA, белые роботы Omron, зеленый робот ТермоЛазера интегрированы во всевозможные технические решения.

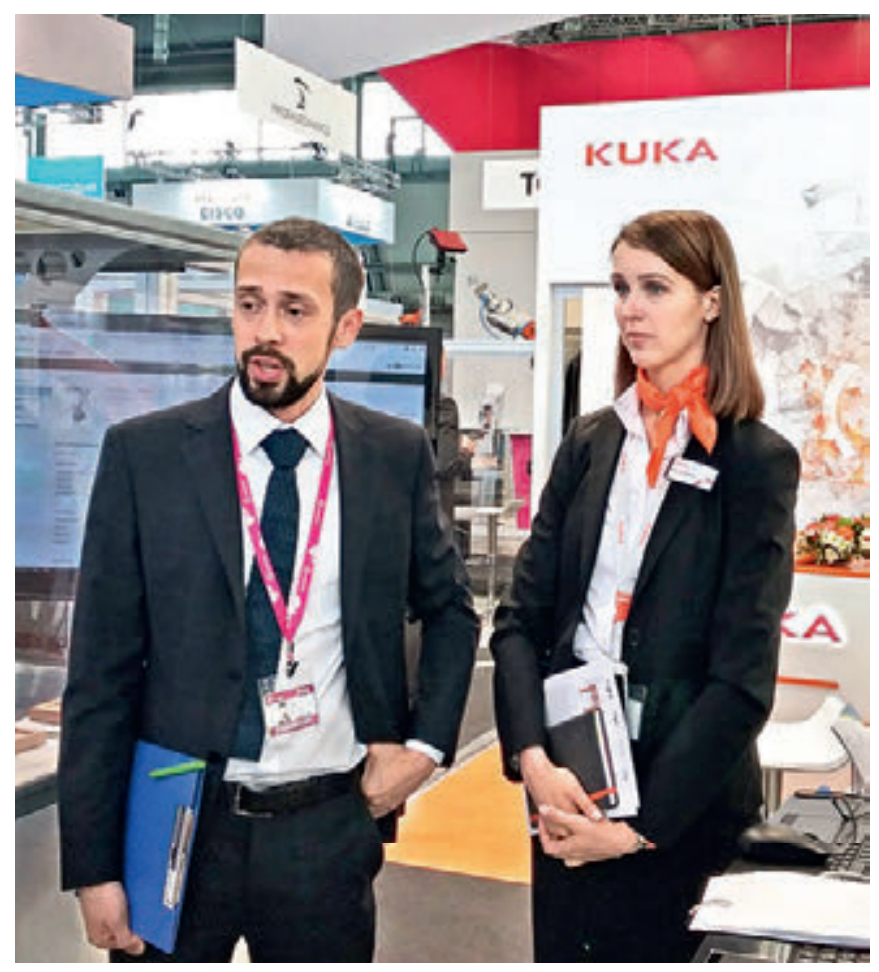

ном. Два лазерных сканера, расположенные на противоположных углах платформы, обеспечивают круговой "обзор" и отвечают за безопасность перемещения мобильной платформы, построение карты местности и ориентацию платформы на этой карте. Если на пути следования появляется неопознанное препятствие, платформа, в зависимости от заложенного алгоритма или останавливается и ждет, когда путь освободится или находит альтернативный маршрут объезда при его наличии и продолжает следовать в назначенную точку. 
Згонников Артем, директор по развитию компании "Инженерно-консалтинговый центр" представил роботизированную систему лазерного 3D-сканирования, разработанную совместно с компанией "Авиатех".

3D-сканер - это устройство для обратного проектирования и оптического контроля геометрии изделий. Роботизированное совместное решение позволяет выполнять 3D-сканирование создаваемых деталей на конвейерной линии с высокой скоростью в режиме non-stop. Полученную в результате 3D-сканирования информацию о геометрических размерах изделия потом можно либо экспортировать в САМ для последующей обработки детали на станке с ЧПУ, либо сравнивать с эталонной CAD моделью для составления метрологической карты отклонений. Можно просто перевести информацию в 3D модель или чертеж как решение задачи обратного проектирования.

Компания Omron Electonics представила решение для задач промышленной автоматизации - робота для перемещения продукции без дополнительной модификации помещения. Об этом рассказал специалист по работе с дистрибьютерами в Уральском регионе компании Omron Electonics Исаев Вадим Евгеньевич.

Компания Omron представляет концепцию цифрового производства и делает упор на роботизацию. Без человека автоматизация невозможна, человек задает алгоритм, программирует все и в дальнейшем обслуживает все эти системы. А вот интересно, в цеху должен быть человек? Все зависит от уровня автоматизации. Есть цеха, где присутствие человека необязательно, когда все автоматизировано: подача продукта, отгрузка и упаковка. Тогда появление человека необходимо в таких цехах только для обслуживания. Разные виды роботов могут перекладывать, укладывать, что-то брать, перемещать, вставлять, вынимать, складировать, сорти-

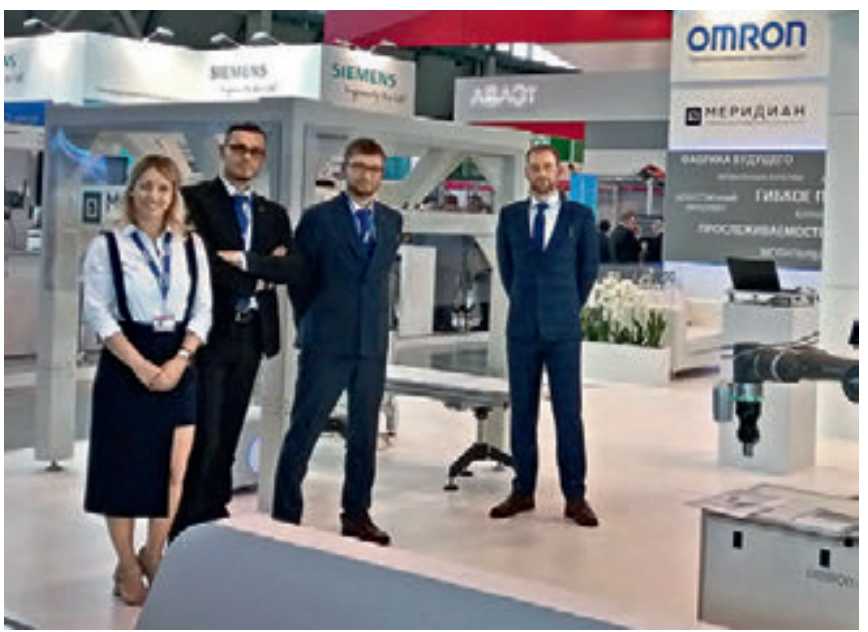

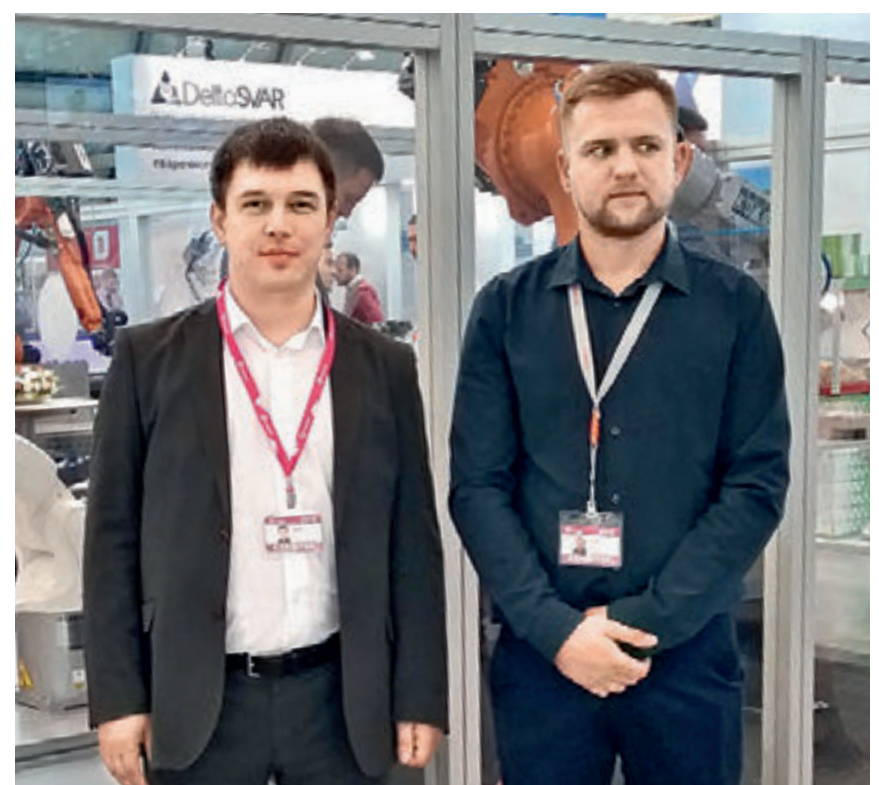

ровать и т.д. Программное обеспечение входит в комплект поставок, но адаптировать его к новому производству, конечно, потребуется. Обязательно! Робот снабжен системой определения местоположения, в которую входят лазерный сканер безопасности и энкодеры, чтобы робот мог работать в часто меняющихся условиях. Он идентифицирует лампы верхнего освещения в случае, если снабжен дополнительной системой определения. Это также позволяет роботам легко перемещаться по большим открытым участкам на больших складах. У специалистов нет необходимости предварительно программировать путь робота Omron. Переналадка роботов требуется, например, при изменении выпускаемой продуктовой линейки. В этом случае благодаря тому, что программное обеспечение робота Omron достаточно открытое и понятное для специалиста, робота можно быстро и легко переналадить. Процесс доступен самим работникам предприятия, и для него не обязательно привлекать дополнительных специалистов.

Компания "Симаргл" из Санкт-Петербурга занимается инжинирингом и производством транспортно-складских систем, в том числе делает различные роботизированные автономные тележки для перевозки разнообразных грузов, в том числе станков. Ведущий инженер компании, выпускник Санкт-Петербургского государственного университета промышленных технологий и дизайна, Толмачевский Николай Романович представил продукт: грузоподъемность тележки, экспонируемой на выставке, 2,5 тонны. Максимальная грузоподъемность тележки, выполненной компанией ранее, составила 60 тонн. 
На выставке японская компания FANUC - один из мировых лидеров в области решений для промышленной автоматизации (мировая доля рынка FANUC в производстве систем ЧПУ составляет 65\%) представила совместное с компанией «Лазерный Центр" решение в области линейной автоматизации с использованием лазерных систем и промышленного робота. Интегрированная в роботизированную линию по обработке металлов система лазерной маркировки МиниМаркер 2 позволяет гибко и качественно производить маркировку деталей в заданный момент технологического процесса.

Среди партнеров компании FANUC - разработчики передовой российской платформы Winnum для промышленного интернета вещей (IIoT). Для управления жизненным циклом изделий необходимы данные, готовые для анализа и принятия решений. В их число входят данные, поступающие с датчиков контроля состояния сложных технических объектов, участвующих в реализации производственных процессов, в их ряду стоят станки с ЧПУ. Благодаря принятию программы Национальная технологическая инициатива (программы по созданию условий для обеспечения лидерства российских компаний на новых высокотехнологичных рынках, которые будут определять структуру мировой экономики в ближайшие 15-20 лет) и созданию в ней направления TechNet, в России растет рынок PaaS (Platform as a Service).

Специалист компании-разработчика программного обеспечения, позволяющего объединить и визуализировать все используемое на производстве оборудование и оптимизировать работу производства, Дмитрий Зуйков рассказал:

Платформа Winnum облегчает и ускоряет процесс создания и запуска приложений для удаленного мониторинга, диагностики и оптимизации работы изделий и процессов их эксплуатации. Мы подключаем роботы, датчики, станки с ЧПУ, забираем с них информацию, создаем цифровой двойник, получаем информацию, на основании которой уже можно проводить анализ состояния производства в каждый момент этапа проведения технологического процесса. Winnum упрощает подключение оборудования и изделий к IoT (Интернет вещей) и дает возможность получать и использовать информацию, получаемую от контроллеров, систем управления или напрямую с датчиков. Обеспечивает простой и быстрый процесс создания приложений для работы с их данными. Благодаря собственным протоколам взаимодействия Winnum обеспечивает безопасное

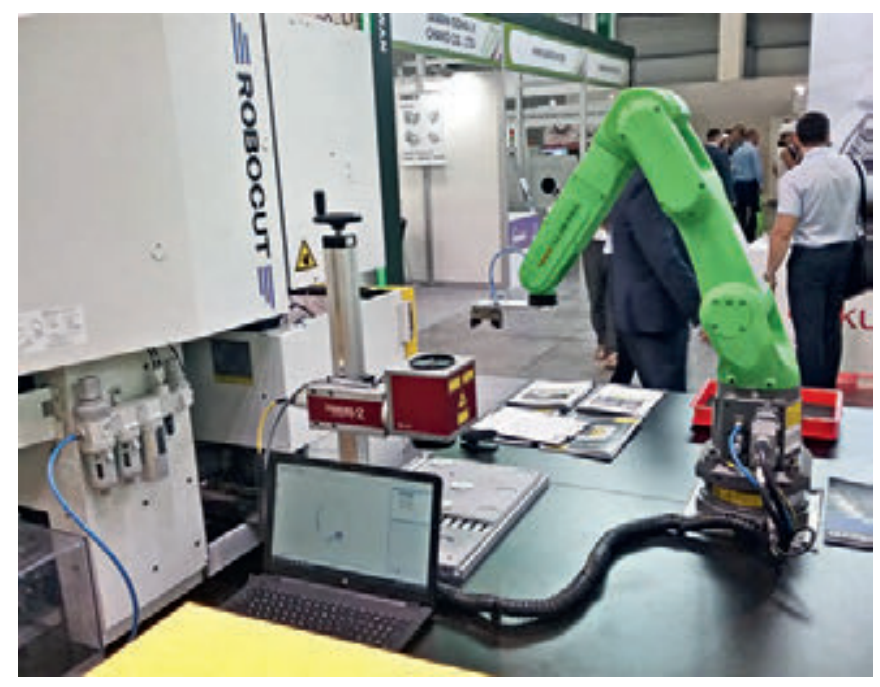

Промышленным предприятиям важно выводить на рынок новую конкурентоспособную продукцию, поэтому уже сегодня им важно приобретать станки с элементами "Индустрии 4.0". Именно для таких производств подготовила свою продукцию компания Signum - партнер FANUC в России с 2016 года. Платформа Winnum взаимодействует с технологическими процессами системы, обеспечивает удаленную диагностику и мониторинг. Помимо сигналов Winnum поддерживает бинарные потоки данных, что позволяет работать с файлами, видео- и аудио-потоками.

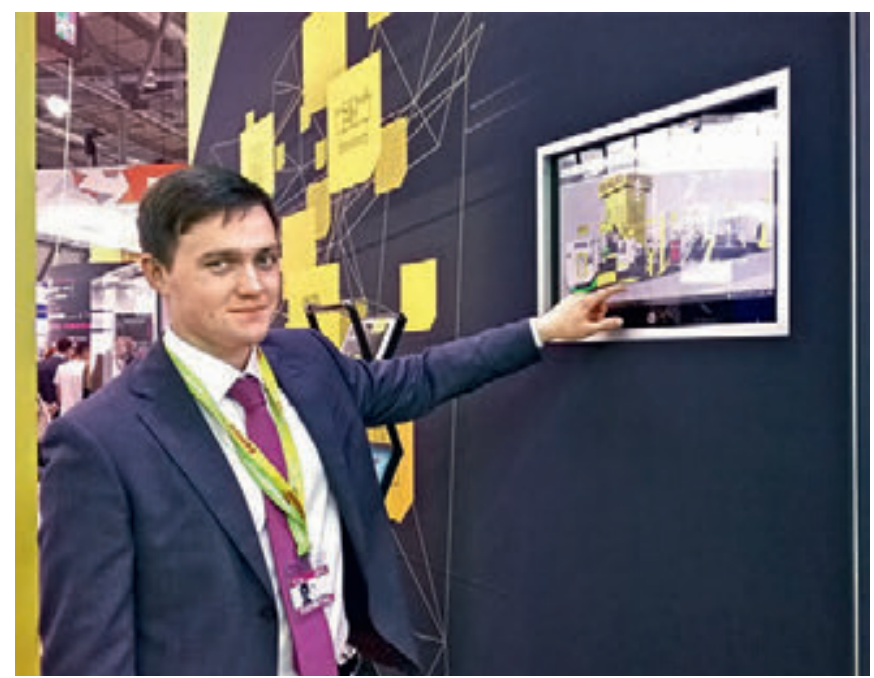

подключение любых устройств и машин к защищенному облаку для целей сбора, преобразования и обработки данных. Это нужно, во-первых, для того, чтобы получить интерактивную картину работы производства, конкретного цеха, участка в реальном времени. Во-вторых, вы можете знать 
состояние, в котором сейчас находится оборудование, оно включено, эффективно работает или нет, в аварии. Также на тачскрин мониторе можно увидеть решение "Цифровой двойник".

Время написания программы для создания «Цифрового двойника" занимает приблизительно одну неделю. Но оно зависит от детализации, от того, сколько работающих механизмов должно быть смоделировано. В каком-то случае это может быть только, например, вращение шпинделя,

\section{Национальная экспозиция Республики Беларусь. Оптический завод "Сфера"} Оптическую продукцию завода "Сфера" представил директор компании Холопица Владимир Антонович.

Без технического зрения нет возможности кон тролировать производственные процессы, и встроенные лазеры не сумеют определить местоположение роботов в изменяющихся условиях. Для этого нужна оптическая системы. Мы делаем разнообразные оптические элементы по чертежам заказчика: линзы (плоские, двояковыпуклые, двояковогнутые, вогнуто-выпуклые), различные призмы, фильтры, дифракционные решетки, сетки. Специалисты завода владеют многими технологиями формообразования, но в своем производстве они сосредоточены на изготовлении плоской и сферической оптики. Сейчас мы модернизировали несколько оптических участков и поставили новое оборудование. В его составе модернизированные шлифовальные и полировальные станки Сморгонского завода, лазерная установка для нанесения сеток. С использованием этой установки завод "Сфера" увеличил выход годных до 90\%, что является высоким показателем и влияет на производительность, а в конечном итоге - на себестоимость создаваемых сеток. На заводе имеется большой вакуумный участок. Компетенции позволяют производить не только серебрение призм, но и наносить просветляющие покрытия, многослойными покрытиями для фильтров. Пользуемся услугами компании "Изовак", если принимается заказ на линзы не только сложной формы, но и со сложным новым покрытием.

Оптическое сырье мы закупаем у разных произ водителей, ориентируемся на то, что закладывает в своих чертежах заказчик. 80\% оптического стекласырья мы покупаем у "Лыткаринского завода оптического стекла", часть сырья покупаем в Китае, небольшую часть покупаем у завода "Оптик". а где-то это может быть уже более детализировано, и, естественно, на это уйдет больше времени.

Winnum - это наша разработка, а экспортировать детализированные 3D-модели можно и из других программных обеспечений, например из Creo или KOMПAC-3D. Мы работаем с сигналами, поступающими напрямую с контроллера, т.е в том виде, в котором вы запрограммировали. Поэтому вы можете увидеть, например, как самый простой вариант - повышение нагрузки на какую-либо ось, повышение нагрузки на шпиндель.

Оптический завод "Сфера" водит в состав холдинга БелОМО (Республика Беларусь), история которого началась в 1957 году с создания производства фотоаппаратов и станков для обработки оптики. Ныне холдинг - это многопрофильное объединение, специализирующееся на разработке и серийном и крупносерийном выпуске высокоточных оптико-электронных, лазерных и оптико-механических изделий специального назначения, приборов для научных целей, кинофотоаппаратуры, наблюдательных приборов (биноклей и прицелов), для инструментов и оборудования медицинского профиля, космической техники. В составе холдинга "Оптический завод "Сфера" решает задачи производства различных оптических элементов: линз со сферическими и плоскими поверхностями, склеенных линз, пластин, клиньев, призм, сеток и шкал, как для серийного производства, так и по индивидуальным чертежам заказчиков. Продукция завода отвечает мировым стандартам и требованиям.

В основном используем марки стекла крон и флинт (крон это оптический материал с ультранизкой дисперсией света и малым показателем преломления, а флинт, наоборот, материал с высокой дисперсией и высоким показателем преломления). К стеклу есть определенные требования, Лыткарино варит стекло 3-й категории и выше. Бывает, что в случаях, когда нет нужных марок стекол, заказываем стекло производства компаний SCHOTT или OHARA. Что заказчик заложил, такое стекло мы и покупаем.

Другая проблема - это сборка оптического объектива: центрировка многолинзовых систем вызвана требованиями к совпадению оптических осей элементов, иначе возникают новые аберрации. Поэтому изготовление линз и сборка объективов - это сложный процесс, который возможен только в про- 


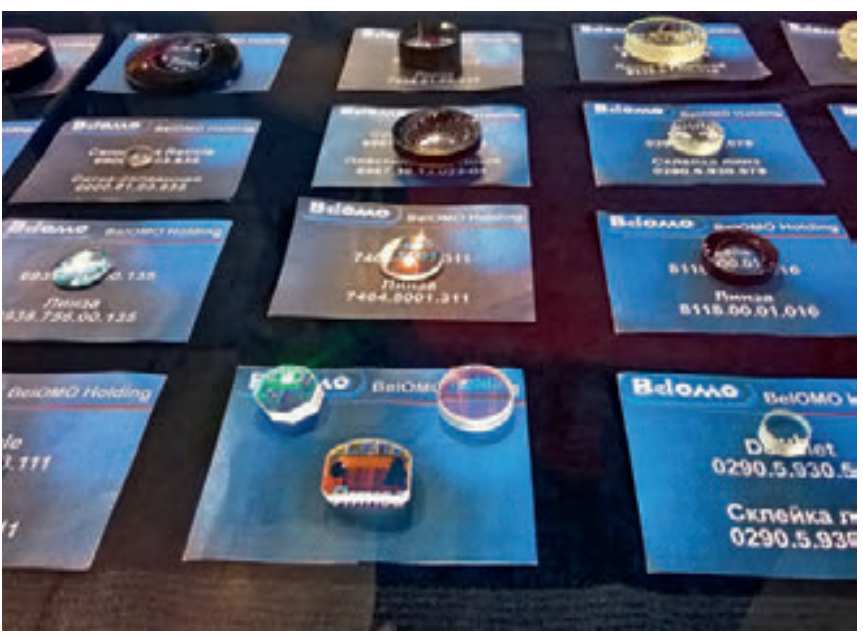

мышленных условиях. На заводе есть участок с центрировочными станками.

Заказы мы выполняем самые разнообразные. Всем без исключения оптическим системам присущи оптические аберрации: хроматические (зависящие от длины волны) и сферические (зависимость фокусного расстояния от радиуса кривизны линзы и высоты падения на нее луча) аберрации, кома, дисторсия (угловая зависимость изображения от фокусного расстояния). Идеальных объективов, как известно, не бывает, и минимизация одного вида аберраций ведет к появлению других аберраций. Поэтому наши заказчики - конструкторы оптических систем - вынуждены идти на компромисс, ставя на первое место решение той задачи, которая должна быть выполнена в первую очередь. Комбинируя оптические материалы, они добиваются исправления аберраций. Уже давно известно, что продольную хроматическую аберрацию собирающей линзы, выполненной из флинта, можно компенсировать за счет рассеивающей линзы, выполненной из крона, - это так называемые ахроматы, притом уже давно существуют и полуапохроматы, и апохроматы. Для их склейки мы в основном используем клей УК74; раньше пользовались бальзамином.

Для коррекции хроматических аберраций конструкторы применяют афокальные компенсаторы различной формы и структуры. Но наибольшее распространение получили склеенные гиперхроматические линзы в виде плоскопа- раллельной пластинки, склеенной из оптических материалов, у которых близки главные значения показателей преломления для основной длины волны, а значения коэффициентов средней дисперсии различаются. Если такая пластинка размещена в параллельном ходе лучей, то, корректируя хроматические аберрации, новые монохроматические аберрации она не внесет. В случае коррекции хроматизма увеличения используют компенсатор, состоящий из двух гиперхроматических линз, разделенных воздушным промежутком значительной величины. Для коррекции сферической аберрации зеркальных, зеркально-линзовых и линзовых объективов используют линзовые афокальные компенсаторы, которые в схеме помещают в параллельных пучках лучей перед объективами. Афокальные компенсаторы представляют собой трехлинзовый компонент (либо несклеенный, либо склеенный), состоящий из двух одинаковых линз, расположенных симметрично относительно симметричной линзы противоположной оптической силы, при этом все линзы выполнены из одного материала.

Казалось бы, что для серийно выпускаемых приборов вопрос коррекции аберраций решен раз и навсегда. Однако появляются новые задачи, и стандартные оптические схемы видоизменяются. Пример - коррекция аберраций в оптических системах для набирающего силу направления VR/AR (виртуальная реальность/дополненная реальность). Искусственно созданная трехмерная среда (VR) и дополненная реальность, строящаяся через отображение реальной среды (AR), обеспечивают пользователю эффект присутствия. При этом

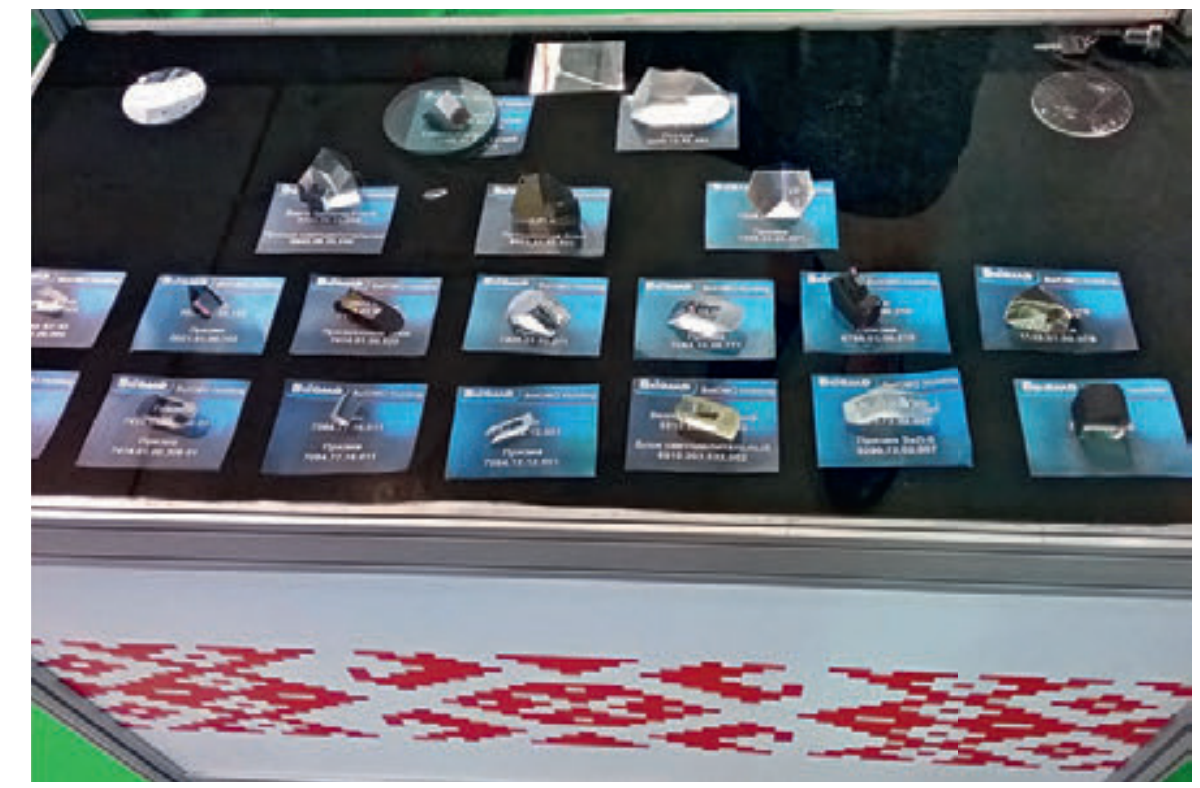


надо понимать, что технология получения изображений для AR обладает всеми теми же оптическими аберрациями. Эти аберрации снижают качество восприятия. Поэтому при проектировании устройств VR/AR необходимо уметь сочетать компактность устройства с высоким качеством изображения, т.е исключить аберрации. Сложные оптические системы с компенсацией аберраций отличаются высокой стоимостью производства, а производство массой продукции страдает отсутствием эффекта реального присутствия. Известны современные попытки создания гибридного объектива с цифровой линзой, т.е. включение цифрового алгоритма для коррекции оптических аберраций изображения, но эффективного чувства присутствия у пользователей они пока не вызывают. Зато использование DO объективов - линзы, соединенной с дифракционной решеткой - такой эффект обеспечивает.

В дни работы выставки прошло вручение Национальной промышленной премии "Индустрия-2019". Ее лауреатом стала группа компаний "Хевел" из Новочебоксарска за внедрение гетероструктурной технологии в промышленное производство. "Хевел" - крупнейшая в России интегрированная компания в отрасли солнечной энергетики.

На конкурс компания "Хевел" представила фотоэлектрический модуль, выполненный по гибридной технологии производства солнечных элементов. В промышленных модулях, собранных из ячеек на основе соединения монокристаллического кремния с тонкими пленками аморфного кремния, получены стабильные электрические характеристики при работе в условиях широкого диапазона температур (от -40 до $85^{\circ} \mathrm{C}$ ), что открывает перспективы использования модулей не только в южных странах, но и в Арктике. Среди критериев, по которым оценивалась заявка на Национальную промышленную
Поэтому конструктора оптических систем интегрируют свои разработки из компонентов с известными коррекционными свойствами. Характеристики оптических стекол зависят не только от материала основы, но и от условий его варки. Например, попадание металлических примесей ведет к повышенному светорассеиванию, проявление которого в готовой продукции непредсказуемо и снижает качество конечного изделия .

Специалисты завода "Сфера" ведут постоянный мониторинг структуры производителей и продуктов рынка оптических материалов и услуг, оценивают уровень цен, спрос на свою продукцию. В этом большую информационную поддержку оказывает наше активное участие в выставочно-ярмарочных мероприятиях. Надеемся, что выставка ИННОПРОМ-2019 повысит потенциал выхода на новые рынки.

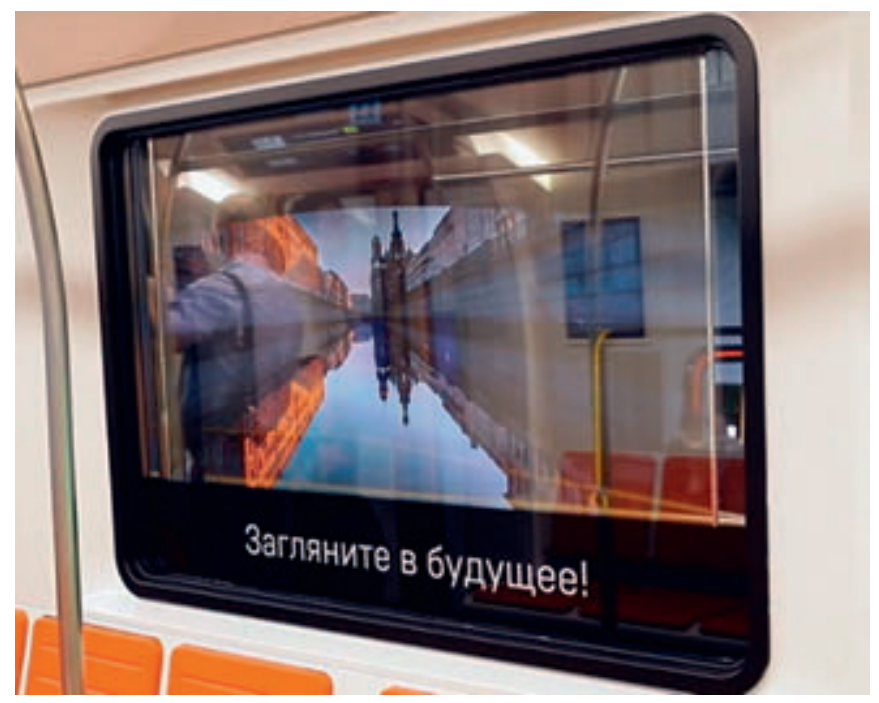

премию, кроме экономического эффекта рассматривалась ориентация на глобальный рынок.

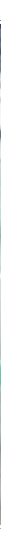


От оптических систем направим свой путь к индустриальной фотонике. По степени популярности в лазерной индустриальной технике впереди всех идет лазерная резка. Японская корпорация Yamazaki Mazak представила и провела консультации по использованию новой модели станка лазерной резки OPTIPLEX 3015 DDL (4 кBT), использующей передовую технологию Direct Diode Laser. Станок OPTIPLEX 3015 DDL (4кВт) может резать медь и латунь (10 мм), к которым сейчас обращено большое внимание.

Благодаря более короткой длине волны, по сравнению с волоконным лазером, достигается высокоскоростная резка тонколистового металла, а также высокоотражающих материалов, таких как алюминий, медь и латунь. Жесткая конструкция станка и ускорение до $2.2 \mathrm{G}$ обеспечивают высокоскоростную резку совместно с инновационным резонатором Direct Diode Laser. В станке установлены передовые интеллектуальные функции и запатен-

Китайская компания Bodor представила лазерный станок для резки широкой номенклатуры изделий от комплектующих из листовой стали до металлических труб, потому что полученные таким образом рез обладает высоким качеством. Об этом рассказал генеральный директор ООО “БОДОР" Михаил смолин.

Российский рынок очень интересен для Bodor. На заводе по производству станков созданы технологические линии очень высокого уровня: используется литая станина. За счет этого на нее можно ставить агрегаты, перемещающиеся с высокими скоростями и ускорениями до 1,5 g (максимальная скорость холостого хода 140 метров в минуту). Если вы повесите агрегаты и узлы с высокими скоростями на сварную станину, то есть большая вероятность того, что со временем из-за усталости металла возникнут вибрации. Литая чугунная станина помогает гасить именно паразитные вибра-

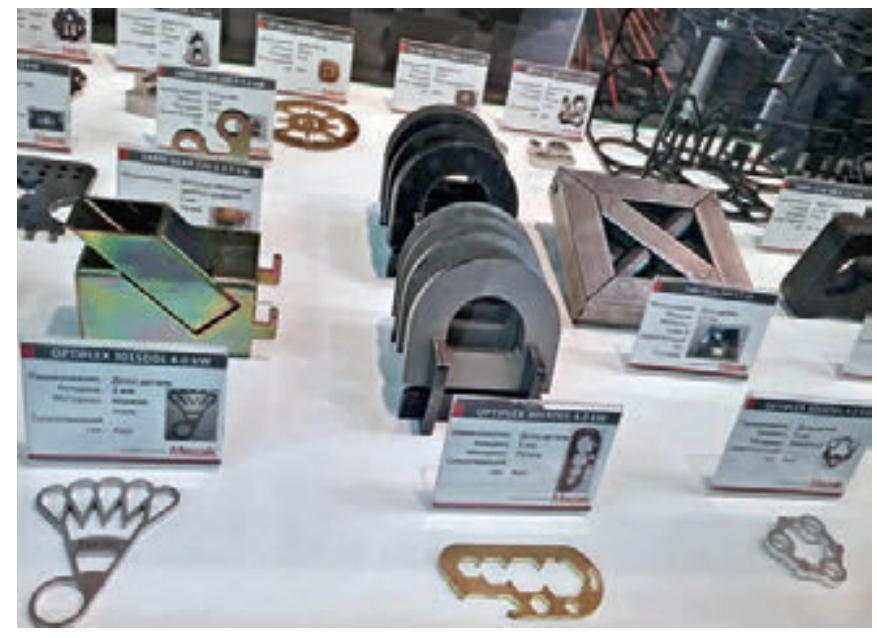

тованные решения, которые обеспечивают непревзойденную поддержку оператора для обеспечения быстрой и качественной работы, не допускающей брака.

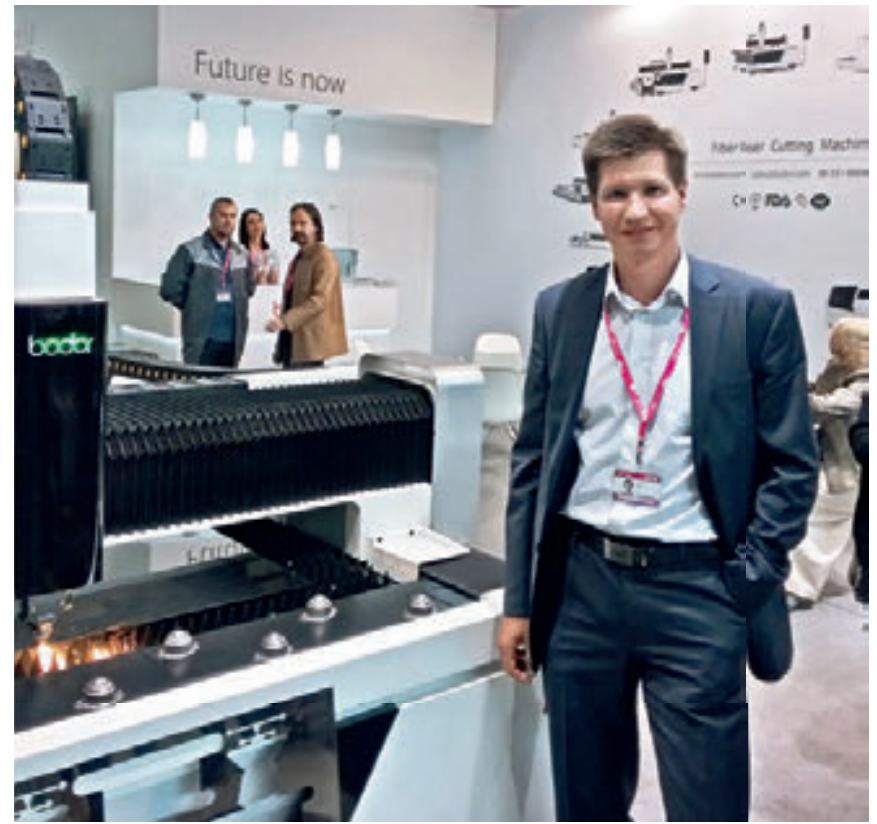

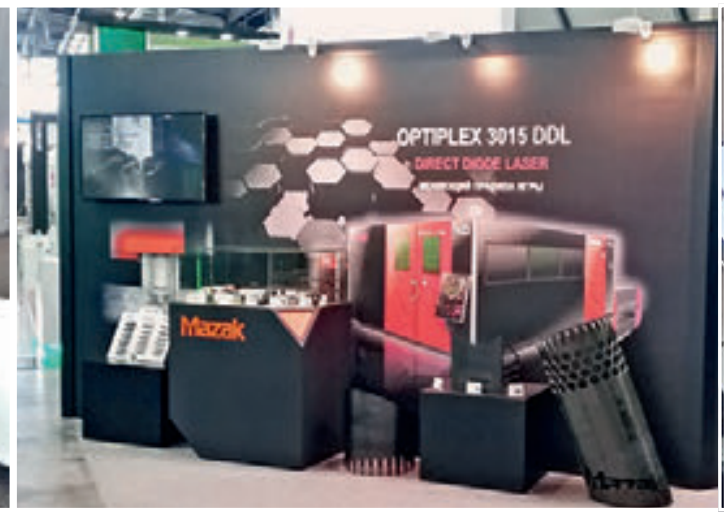

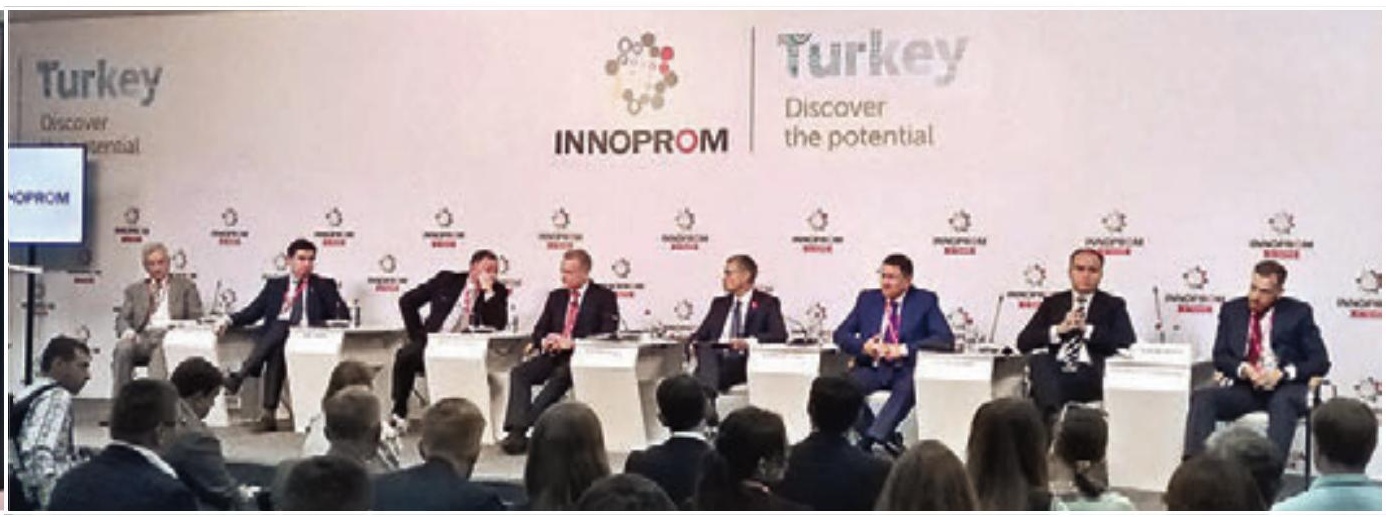


ции, которые возникают в работе, и как следствие это увеличивает срок жизни станка.

И хотя многие компании заявляют о достижении в своем оборудовании для лазерной резки величины ускорения до $5 \mathrm{~g}$, но такие запредельные ускорения прекрасны и оправданы только тогда, когда речь идет об источнике более 6 киловатт, и у заказчика имеется роботизированная система автоматической загрузки и выгрузки без участия оператора в управлении. Когда на высоких скоростях мы берем с вами мощный источник и режем толстый металл, это неоправданный выбор оборудования, потому что лазер режет с приемлемым качеством металл толщиной 20-25 мм. Если же брать более толстый лист металла, то проще использовать либо плазменную, либо гидробразивную резку.

Мы адекватно подходим к рынку. Не во всех российских регионах представлены поставщики хорошего газа, используемого при лазерной резке. Это одна из причин, почему люди покупают азотную станцию. Кислородную станцию купить накладно, а азотную - можно. Все поставщики лазеров гово-

\section{Мобильный лазерный комплекс для термического упрочнения поверхностей деталей от компании "ТермоЛазер"}

На выставке иннОПРОМ-2019 компания ООО "ТермоЛазер" экспонировала мобильный лазерный комплекс для термического упрочнения поверхностей деталей. Об этой новинке членам редакции журнала ФОТОНИКА рассказал Игорь Ручай, начальник конструкторского технологического отдела компании.

На выставке представлена наша новинка мобильный роботизированный комплекс на базе диодного лазера мощностью 3-5 кВт, работающий на длине волны 980 нм. В качестве манипулятора мы используем 6-ти осевой робот с сингулярной системой. Робот установлен на мобильную автономную тележку тоже нашего собственного производства, тележка работает на аккумуляторах и управляется с помощью дистанционного пульта. Преимущество данной конструкции в том, что робот может на территории заказчика приблизиться к какой-то крупногабаритной детали, либо осуществлять межцеховые перемещения. Для этого требуется всего лишь один оператор. Сами понимаете, есть такие детали, как 30-ти тонные валы в судоремонтной промышленности, которые невоз- рят, что нужно резать газом такой-то чистоты. Но мы люди разумные и понимаем, что это не всегда возможно. Да, это сказывается немного на скорости и чуть-чуть на качестве. Если нет возможности покупать такой чистый газ, режьте тем, что есть. У Bodor есть автоматизированные интегрированные решения с автоматической выгрузкой листового металла для лазерной резки, где идет автоматический робот-укладчик. Есть решения с автоматической размоткой 20-тонного листа. Такие линии работают в Австралии и не только.

Однако в разных странах популярность различных видов роботизированных комплексов отличается друг от друга. Если в Германии, например, наблюдается спрос на роботизированные комплексы, совмещенные со сварочными лазерами, то в России преимущество на стороне роботизированных комплексов с лазерными головками для наплавки. В нашей стране любят все ремонтировать и восстанавливать. В последние годы наметился растущий спрос на лазерное упрочнение материала, на лазерную наплавку, лазерное ударное упрочнение.

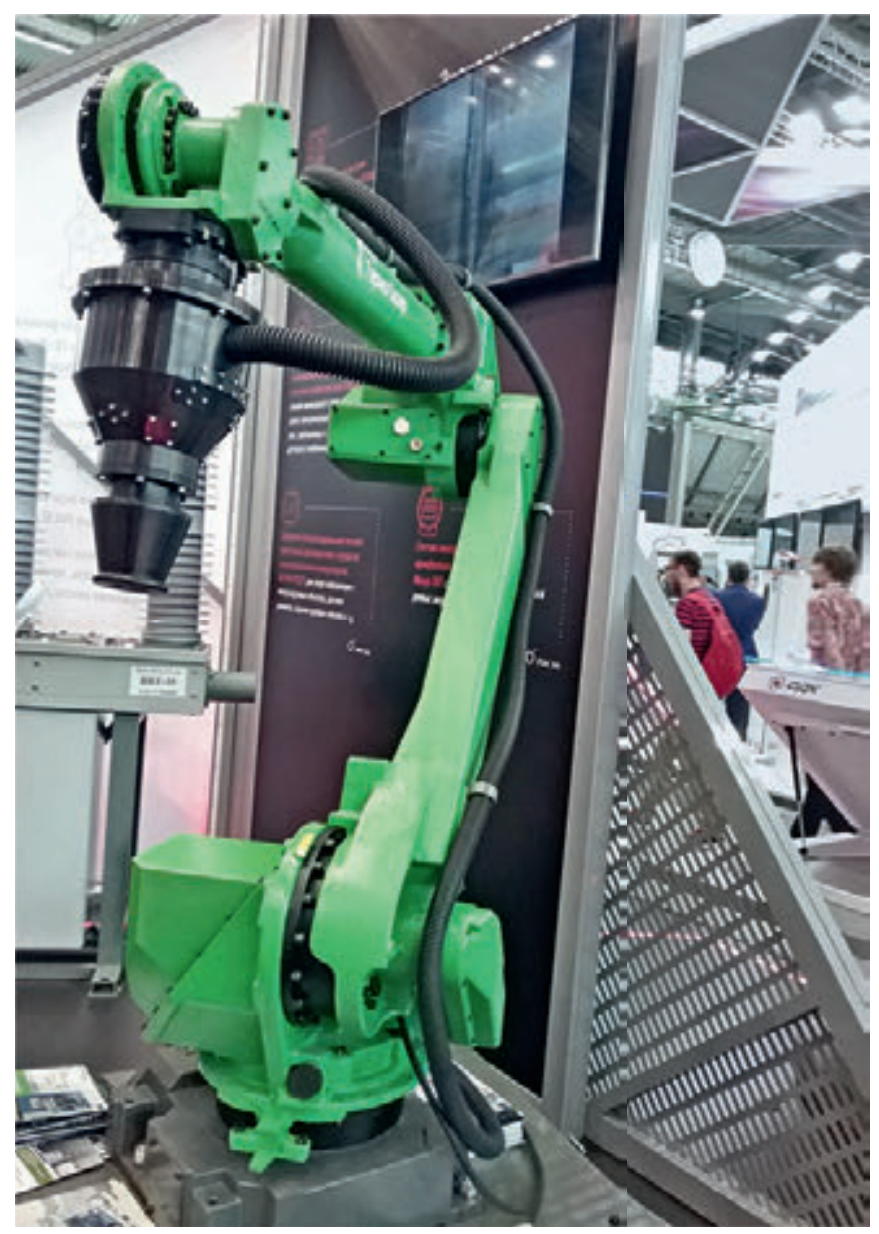


можно привезти. При этом вес самой установки 1,2 тонны.

Комплекс предназначен для наплавки порошком, для производства которого имеется собственное действующее опытно-промышленное производство. Методом диспергирования расплава с поверхности катода потоком инертного газа компания "ТермоЛазер" получает сферические бескислордные порошки с разбросом в нанометровом диапазоне размеров 20-40 нм и в микрометровом диапазоне с разбросом 20-40 мкм. Получить идеально ровную сферическую форму порошка - это очень серьезная проблема, которую мы решили .

Компания разработала и производит широкую линейку лазерных комплексов. Для лазерного упрочнения в компании разработаны два вида технологии: либо в качестве присадочного материала для наплавки используется наплавочная проволока, либо порошок.

Лазерный комплекс позволяет обрабатывать наружные поверхности изделий сложной формы. Среди них: штампы, пресс-формы, железнодорожные колесные пары нового типа, которые разработаны специально для того, чтобы снизить нагрузку на железнодорожное полотно и повысить допустимую скорость движения поездов, детали для различных отраслей промышленности. Изюминка высокоэффективного роботизированного комплекса проявляется при выполнении гибридных операций в гибком производстве. Комплекс обладает многофункциональной манипуляционной исполнительной системой, обеспечивающей необходимые параметры управляемого движения и взаимодействия рабочих инструментов. Для этого на этапе проектирования были проанализированы элементы кинематической цепи манипуляторов, исключающей сингулярности. Работа исполнительных устройств манипуляционных роботов происходит в условиях взаимного влияния звеньев через статические и динамические нагрузки. Компенсация этого взаимовлияния способствует улучшению энергодинамических характеристик робота.

В продуктовой линейке нашей компании есть множество лазерных комплексов для обработки наружных поверхностей деталей, т.е. для закалки. При термообработке лазерный луч нагревает внешние слои изделия, затем происходит быстрое охлаждение, и формируется жесткая мартенситная структура. Для примера: если поверхность детали из конструкционной
От природы и структуры используемых материалов зависят свойства конструкционных соединений изделий машиностроения, транспортных трубопроводов, мостовых коммуникаций. Они определяют надежность и долговечность оборудования. Но в процессе создания изделий, а затем и их работы эксплуатационные характеристики поверхностных слоев деталей ухудшаются по сравнению с материалом основы. В случае, когда узлы механизмов подвергаются циклическим знакопеременным нагрузкам или тепловым нагрузкам, в поверхностных слоях образуются трещины, и их рост может привести к разрушению детали. Вернуть механизмам и элементам оборудования заложенные конструкторами свойства износостойкости, усталостной прочности, коррозионной стойкости, прочности посадок позволяют технологии лазерного упрочнения: закалки, наплавки и легирования. Технологии лазерного упрочнения поверхности родились давно, вскоре после создания первых мощных лазеров, и начали быстро развиваться с появлением твердотельных лазеров. Компания ООО "ТермоЛазер" (г. Владимир), имея задел по результатам исследований влияния лазерных методов на повышение сопротивления усталости, длительной прочности деталей машин и конструкций, эксплуатируемых в условиях повышенных температур и циклических нагрузок, разрабатывает и выпускает лазерные комплексы. Компания "ТермоЛазер" была создана в 2010 году, а в 2015 году получила поддержку от "Фонда развития промышленности" (www.frprf.ru) в виде займа, срок возврата которого - конец 2020 года. Уже через два с половиной года компания вывела на российский рынок автоматизированное оборудование для лазерного термоупрочнения крупногабаритных деталей.

легированной стали 38ХН3МА до лазерной обработки имела твердость 29-32 HRC, то после упрочнения эта характеристика достигает величины 56-59 HRC. Также есть лазерное оборудование для внутрицилиндрической обработки деталей диаметром от 80 мм и длиной до 6 метров. При обработке внутренних поверхностей цилиндрических изделий, например труб или буровых штанг, максимальная глубина обработки составляет три метра. Поэтому общая внутрицилиндрическая длина обрабатываемого изделия достигает шести метров. 

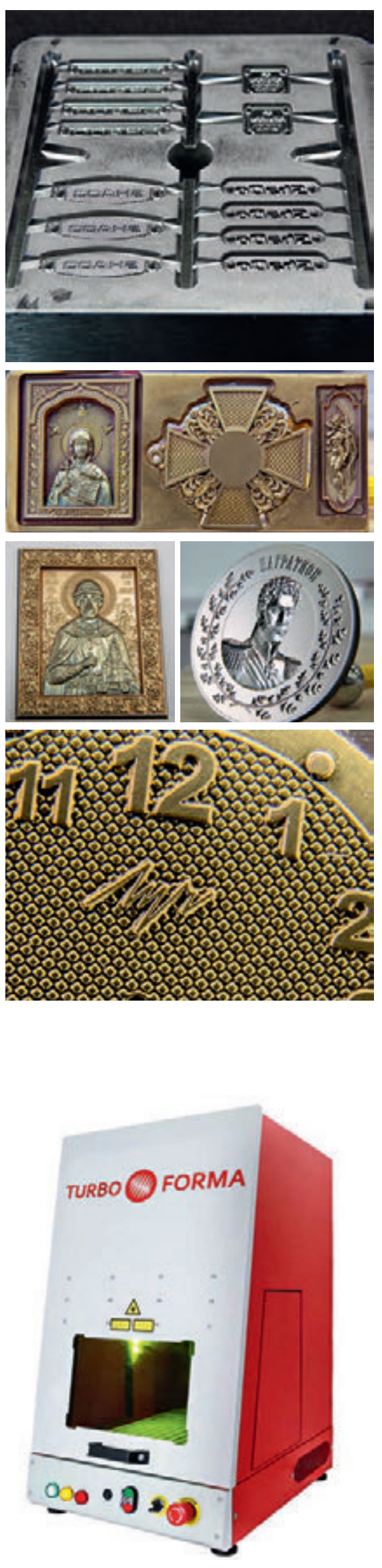

\section{Компания "Лазерный Центр"}

Логистическая стратегия автоматизации производства не может существовать без кодирования информации об изделии. Мар кировка изделий с помощью цифровых и штриховых кодов наносится непосредственно на материал самого продукта металл, пластик, стекло. В этом случае исключается подмена кода, которая возможна при нанесении маркировки на промежуточные носители в виде этикеток или упаковки. Лазерные маркировщики компании "Лазерный Центр" способны за 10 микросекунд нанести один штрих. Эта способность важна в массовом серийном производстве, чтобы скорость нанесения маркировки не ограничивала скорость производства изделий.

Компания "Лазерный Центр" на каждой промышленной выставке демонстрирует новые технологии и оборудование. Выставочная экспозиция компании включает большое количество разнообразных лазерных станков для различных технологических операций. В первый день работы выставки ИННОПРОМ-2019 стенд "Лазерного Центра" посетили официальные делегации Республики Татарстан во главе с президентом Миннихановым Р.Н., Министерства промышленности Республики Беларусь во главе с министром Утюпиным П.В., руководители различных предприятий и организаций. И действительно, продукция у многих посетителей вызвала интерес.

Компания "Лазерный Центр" представила станки для лазерной маркировки и гравировки ("Минимаркер-2" и "Турбомаркер»), для лазерной сварки («Фотон-компакт" и «Фотон-150") и прецизионной резки (RX-150) металлов и сплавов, специальные лазерные системы обработки материалов электронной техники ("МикроСЕТ»), установки лазерноэрозионной обработки ("Турбоформа»). В установке "Турбоформа" реализована новейшая, не имеющая аналогов на российском рынке система трехмерной лазерной гравировки высочайшего качества, реализующая новую технологию лазерной 3D-гравировки лазерно-эрозионную обработку материалов LaserBarking ${ }^{\circledR}$. Полностью автоматизирован ${ }^{-}$ ный лазерный комплекс серии "ТурбоФорма" позволяет быстро и качественно производить обработку штамповых сталей с высокой твердостью и получать готовый инструмент размером до 100×100 мм. Также "Лазерный Центр" представил инновацион ${ }^{-}$ ные решения для непрерывной гравировки больших площадей с очень высокой точностью “сшивки" гальвополей (рабочее поле лазерной головки).

Сергей Горный, генеральный директор компании «Лазерный центр", объяснил:

Технология получила название Laser Barking. Barking в английском языке имеет много разных значений, и одним из них является "окоревание». Окорка - это процесс зачистки внешнего слоя стволовой части дерева (снятие коры), происходящий после того, как с него будут удалены ветви и сучья. Еще "to bark" переводится с английского языка как "собака лает по-собачьи" - аналогия с собакой, выгрызающей металл любой твердости с фантастическим качеством и на любую глубину. Технология лазерноэрозионной обработки основана на механизме контролируемого удаления тонких слоев обраба- 
тываемого материала в результате воздействия сфокусированного лазерного излучения, параметры которого варьируются по специально разработанному ПО. Качество поверхности получается на уровне полировки материала или материала, прошедшего обработку на полировальном станке

Компания "Ювелирный дом Чамовских" из Екатеринбурга для производства своих изделий из ювелирных металлов и сплавов тоже не использует пресс-формы, отлитые обычными способами. Ювелиры компании используют аддитивное выращивание. Компания славится внедрением инновационных лазерных технологий: резки, сварки и гравировки.

Гравировка металла на различную глубину позволяет вводить в канавки эмаль. И заканчивая первую часть обзора, поделимся советом, который дали в компании "Ювелирный дом Чамовских" о том, как отличить натуральный жемчуг от искусственного. Можно подержать оба изделия в руке, и тот жемчуг, который окажется холоднее, тот и будет натуральным, а жемчужина, которая окажется теплее соседки, искусственная.

Зато мощный тепловой поток, который вы ощутите, подойдя к светодиодному экрану, оказывается неизбежным атрибутом экрана. Потому что это свойство светодиодов: нужен слишком высокий ток, который подается на светодиоды для того, чтобы они светились. Но вот буквально через 5 лет нас ждет революция. Каждый пиксел будут составлять 3 светодиода размером всего 20 микрон. О футуристических прогнозах, о выращиваемых искусственных сапфирах рассказали сотрудники компании "Монокристалл" из Ставрополя. Компания занимает 50\% мирового рынка производства сапфира для светоизлучающих диодов. Но об этом читайте уже в продолжении обзора выставки ИННОПРОМ-2019... высокого класса. Мы видим, что у технологии большой потенциал применения. Тем более технология позволяет очень быстро изготавливать пресс-форму. Обычными способами пресс-форма делается за 3-6 месяцев, а по технологии LaserBarking на ее изготовление затрачиваются только десятки часов.
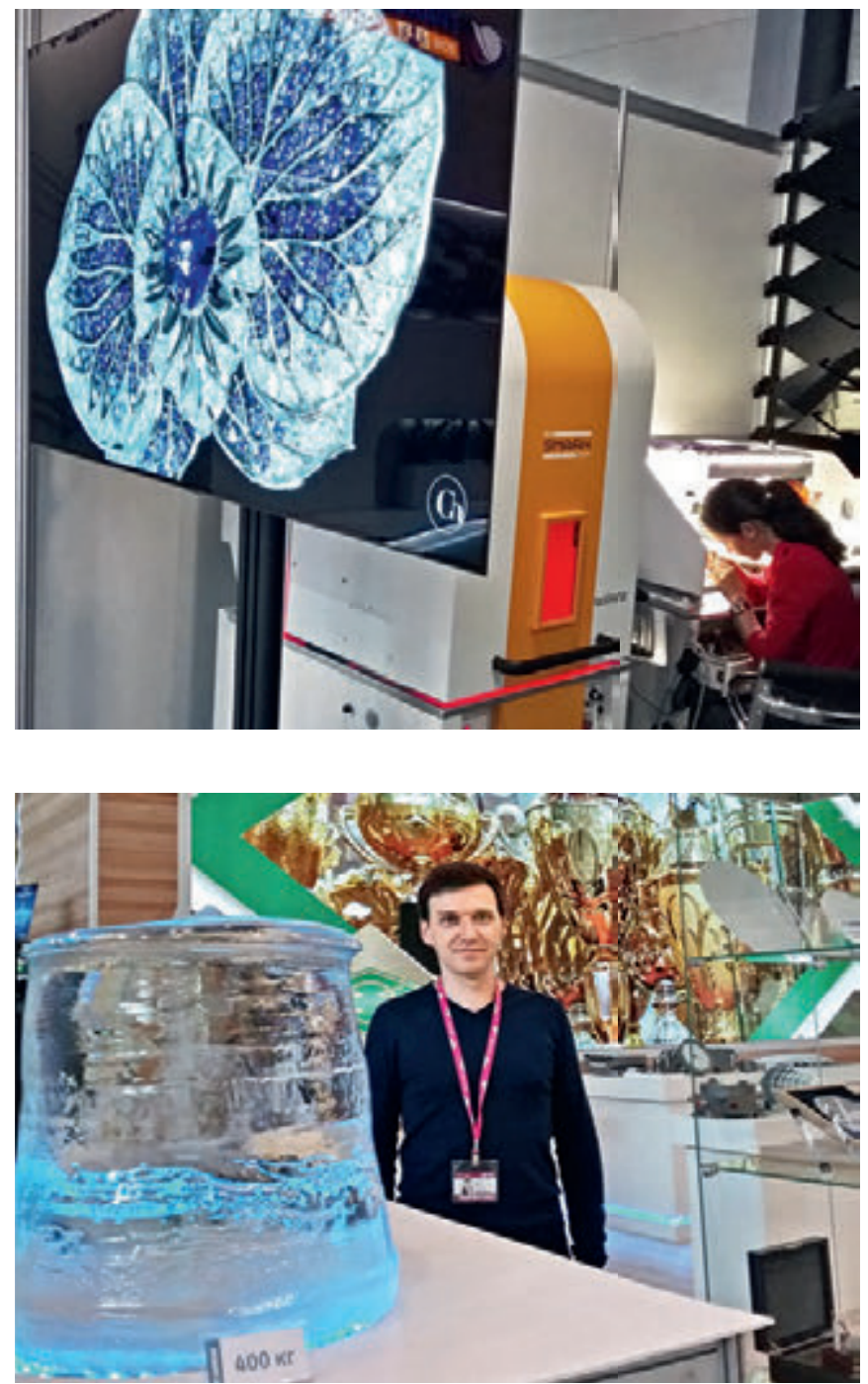

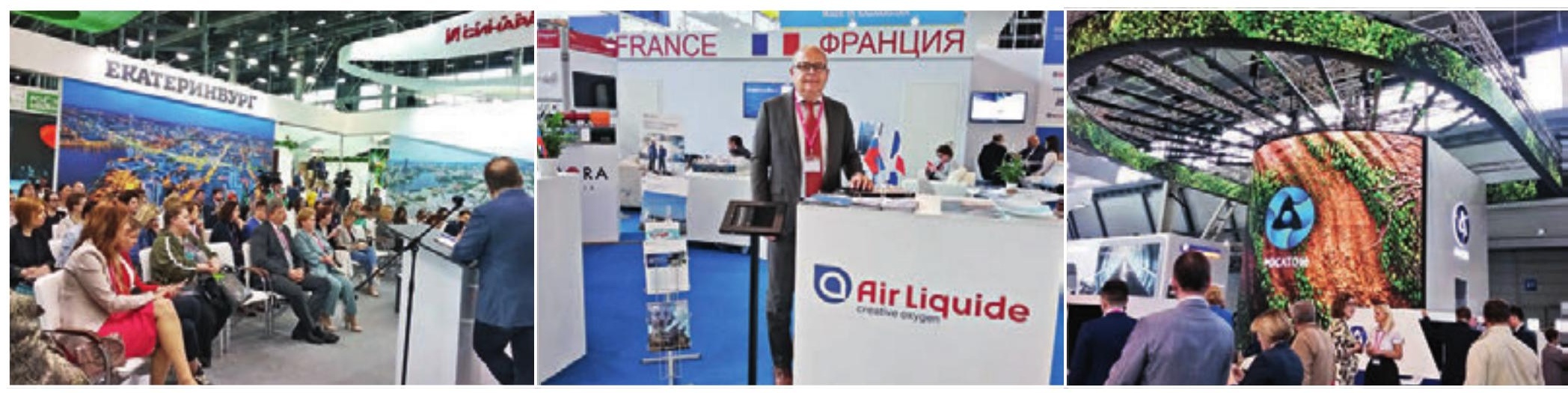

Photonics VOL. 13 № 72019631 